\title{
Self-Regulation of Learning and its Association with Motivation and Attitude in Engineering Students
}

\author{
Waldyr Fong Silva ${ }^{1 *}$, José D. Patino Moncada ${ }^{2}$ and Jose Jaimes Morales ${ }^{3}$ \\ 'Metrology Program, University of Cartagena, GIMIFEC Research Group, Cartagena-Colombia; \\ wfongs@unicartagena.edu.co \\ 2Economy Program, Universidad de Cartagena, Research Group on Information Technology, Entrepreneurship \\ and Society. Cartagena-Colombia; jpatinom@unicartagena.edu.co \\ ${ }^{3}$ Nursing Program, University of Cartagena, MAAS Metal as a Service Research Group, Cartagena-Colombia; \\ jjaimesmor@yahoo.es
}

\begin{abstract}
Objectives: A study was carried out that evaluated the association between student attitude and motivation with the self-regulation of learning in Engineering students, in an estimated one thousand two hundred and fifty (1250) students between the years 2014 and 2016. Methods/Statistical Analysis: An inferential statistical study was performed. Selfregulation of learning was assessed using the SRLI (Self-Regulation of Learning Inventory), which is a questionnaire consisting of 80 questions weighted from 1 to 5 on the basis the linker scale. To quantify the Learning Self-Regulation score, each scale of the instrument was quantified separately and the total score is the sum of each of the scales that make it up. The Chi-Square test between self-regulation of learning and the variables Student Attitude and Motivation was used to know if there is statistical significance between them taking into account the hypothesis test. Findings: The results indicate that there is an important association of statistical significance between attitude and self-regulation of learning, motivation and self-regulation of learning and between attitude and student motivation at a level of significance of 95\%. Application/Improvements: The instrument for measuring Self-Regulation for Learning (SRLI) is considered a reliable and effective tool. It allows identifying weaknesses in students with the aim of adopting strategies and advising the teaching-learning processes according to the considerations that a self-regulated student must fulfill. In addition, knowing the statistical association between self-regulation of learning, attitude and motivation will allow professors to design improvement plans that contribute to improve decision-making in students and, at the same time, allow them to solve with relative ease problematic situations related to their area of professional performance.
\end{abstract}

Keywords: Association, Attitude, Motivation, Self-Regulation, Statistic, Students

\section{Introduction}

In Colombia, according to data from the system for the prevention of dropout of Higher Education, the dropout rate per period in Colombia for students of higher education is $9.3 \%$, while in other countries such as Brazil, the United Kingdom and the United States they report rates of $18 \%, 8.6 \%$ and $18.3 \%$ respectively, despite being countries with great advances in their education system. In other countries, such as Argentina, Venezuela, Chile, Mexico and Colombia, the dropout rate per cohort is $43 \%, 52 \%$, $54 \%, 42 \%$ and $46.1 \%$, respectively. This means that for every 100 students entering the higher education system about $50 \%$ (almost half), they do not finish their studies ${ }^{1}$. This motivates studies that evaluate possible causes that affect relevant aspects such as the self-regulation of learning in university students and their possible relation with attitudinal and motivational aspects.

In 2 the attitude is conceived as the predisposition for reach a goal, favorably or not towards it. It is also con-

*Author for correspondence 
ceived as the process of learning to interrogate, learn to learn and have more disposition to problematize their learning experience, according 3 . In the same way, the attitude manifests itself during the evaluation that the students do of their learning process. $\operatorname{In}^{4}$, this can be positive or negative according to their emotional characteristics and is articulated with the cognitive process facilitating it or not.

In $\underline{5}$ the orientation to success predominates as one of the attitudes towards the study while, on the other hand, the effort is considered as a fundamental element to avoid failure. With respect to the achievement of learning, students attribute it mainly to themselves, in the face of chance or external circumstances. Also ${ }^{\underline{6}}$ the attitude towards learning adopted by the university engineering student, makes him a self-regulated student, who with a positive attitude reaches his goals and goals with relative ease.

$\mathrm{In}^{\mathrm{z}}$ considers that there is a statistically significant relationship between cognition and the engineering student's attitude at a $95 \%$ confidence level. That is, an engineering student abstracts, analyzes, processes, stores, retrieves, creates, internalizes meanings and is creative and imaginative. This allows you to transform concepts and solve problems. These factors make it reach academic success in a self-regulated and easy way.

In the same way, motivation is a more personal and conscious behavior that the university student should adopt in the face of his or her learning. Although this is not necessarily intrinsic, it must include attitudes towards the teaching-learning process from the perspectives of orientation towards the study as those posed by $\frac{8.9}{9}$ personal reasons according $\frac{10,11}{}$ and attitude towards the task according $\underline{12}$.

$\operatorname{In} \frac{13}{13}$ there is a statistically significant relationship with a 95\% confidence level between motivation and self-regulation of learning in engineering students. According to this author, this is due to students having an intrinsic motivation that comes from beliefs, professional love, proactivity, fear of public failure and predisposition to achievement which makes them able to transform information and concepts by developing their own abilities related to their professional practice.

Motivated learning according to the statements of Pint ${ }^{14}$ is related to the student's motivation to acquire skills, ability and strategies, in which prior self-efficacy and the implication towards the task is considered relevant.
In the same way, what differentiates a student with academic success from one who does not have it, is the degree of self-regulation that he possesses as posed by ${ }^{15-18}$. A student who can self-regulate his learning is intrinsically motivated, self-directed, self-monitored and self-evaluative; is a flexible person who adapts to the changes that arise in his environment $\frac{19}{}$.

The importance of this research lies in evaluating the degree of statistical significance that exists between the attitude, motivation and self-regulation of learning in the students of the Engineering programs of the University of Cartagena through an inferential statistical analysis and contingency tables in order to define pedagogical-and ragogical strategies that contribute to minimize desertion in the first semesters of these programs.

\section{Materials and Methods}

\subsection{Statistical Methods}

An inferential statistical study was performed. The sample size was calculated as suggested by $\mathrm{I}^{\mathbb{Z}}$ for populations of less than 100,000 individuals.

\subsection{Population and Sample Size}

The study participants were regular students of the third semester of the programs of Chemical Engineering, Civil, Systems and Food of the University of Cartagena between the periods 2014 and 2016. Of the total, each academic program contributed the $25 \%$ of total sample. The ages of the students oscillated between 17 and 22 years. The sample was intentional and $75 \%$ corresponded to males and $25 \%$ to females.

The sample size is calculated ${ }^{z}$ by Equation (1):

$$
\mathrm{N}=\frac{\sigma^{2}{ }^{*}{ }^{*} p^{*} \mathrm{q}}{\mathrm{e}^{2 *}(n-1)+\sigma^{2} p^{*} \mathrm{q}}
$$

Where:

$\mathrm{N}$ : Number of elements that the sample must have; $\sigma$ : Level of confidence or risk chosen.

p: Probability that an element is selected in $\%$ estimated; q: Probability that an element is not selected $(q=p)$; e: Error allowed; n: Number of population elements. 


\subsection{Variables, Phases and Reliability of the Test}

\subsubsection{Variables}

The variables used in the research were classified into two (2) categories (independent and dependent):

- Independent variable: Attitude and motivation of the student.

- Dependent variable: Self-regulation of learning.

The Learning Self-Regulation Level was organized into two categories: ARB: Low self-regulation (scores below 300 points $(\mathrm{ARB}<300)$ ) and ARA: High self-regulation (scores equal or greater than 300 (ARA $\geq 300$ )). The independent variables were classified into two categories: 1 . Low Student Attitude (AEB) $(171<\mathrm{AEB} \leq 213.75$ points) and high student attitude (AEA) $(213.75<\mathrm{AE} \leq 285) .2$. Low motivation ( $\mathrm{MB})(\mathrm{MB}<75$ points or less) and high motivation ( $\mathrm{MA} \geq 75$ points out of a total of 100 points).

For the analysis, the Lindner, Harris and Gordon questionnaire was applied ${ }^{15}$ which consists of 80 weighted questions from 1 to 5 on the linker scale. The instrument was validated as reported by ${ }^{19}$.

\subsubsection{Phases}

The project was carried out in three (3) phases: In the first, the attitude and motivation factors were identified through a survey. In the second phase, the Self-Regulation Inventory for Learning (SRLI) designed 15 was applied to the student population under study. In phase 3 the independent variables were crossed with the dependent one (self-regulation of learning), evaluating the statistical significance between them and later the bar diagram of the relational analysis was constructed.

\subsubsection{Reliability of the Test}

To determine the internal consistency (reliability) of the test was used the ${ }^{20}$. Self-regulation of learning was assessed using the SRLI (Self-Regulation of Learning Inventory), which is a questionnaire designed by $\frac{15}{15}$ consisting of 80 questions weighted from 1 to 5 on the basis the linker scale.

\subsection{Statistical Analysis}

The Chi-Square test ${ }^{21}$ between self-regulation of learning and the variables Student Attitude and Motivation was used to know if there is statistical significance between them.

\subsection{Test of hypothesis}

Ho: Null hypothesis: "There is no relationship between self-regulation of learning and student attitude and motivation" and the results are a product of chance.

Ha: Alternative Hypothesis: "If there is a relationship between self-regulation of learning and student attitude and motivation" and the results are not a product of chance.

\subsection{Contingency Tables}

The contingency tables were constructed of $2 \times 2$ dimensions (two rows and two columns) and were

Formed in the following manner:

- Self-regulation of learning - Student attitude.

- Self-regulation of learning - Motivation.

- Student Attitude - Motivation.

\section{Results and Discussion}

The population size was 1250 students. Applying equation 1 to this population yielded a sample size of 211 individuals. However, in applying the surveys were homogeneously made to 9 students per academic period, 4 programs and 6 academic periods for a total of 216 students. The study was carried out between the academic periods 2014-1 and 2016-2. The reliability of the instrument used (SRLI) was made by the in ${ }^{20}$ which yielded an average value of 0.91 indicating a high internal consistency of the test. To quantify the Learning Self-Regulation score, each scale of the instrument was quantified separately and the total score is the sum of each of the scales that make it up.

The Chi-square test was made for the analysis of the relationship between the dependent variable SelfRegulation of Learning and independent variables: Attitude and student motivation. In the same way, it was applied to evaluate the relationship between Attitude and motivation of the student. Table 1 shows the values of statistical significance $\mathrm{p}$ where it is observed that there is a relationship of high statistical significance between selfregulation of learning and attitude $(\mathrm{p}<0.05)$, between self-regulation of learning and motivation $(\mathrm{p}<0.05)$ and between Student Attitude and motivation ( $\mathrm{p}<0.05)$.This means that Self-Regulation of Learning and attitude are 
statistically related, that is, a student with a positive attitude to achieve a goal is self-regulated, verifying with this the statements of in 2 . In the same way, a student with a positive attitude and who has the ability to interrogate, know how to learn and who continuously problematizes his or her learning experience is a self-regulated student according the assertions ${ }^{3}$. In the same way, a student with a positive attitude facilitates his academic exercise and his learning process since he also develops efficient cognitive processes that help him to be a self-regulated student,

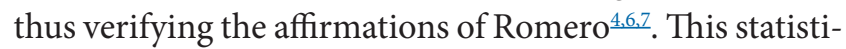
cal significance also allows verifying the assertion $\frac{5,12}{}$ since the attitude oriented to success supported in the personal effort of the student turn him into a self-regulated student.

In the same way, self-regulation and student motivation are statistically related, that is, a student with a personal motivation that is aware of learning and that includes positive attitudes and oriented towards study, with personal reasons, that pursues professional goals as a human is a self-regulated student thus proving the claims $\underline{\underline{8-11}}$. In the same way, the motivated student develops a motivated learning and is able to acquire skills, develop skills and strategies of self-regulated learning, verifying in this way the affirmations of Pintrich ${ }^{14}$. In addition, this relationship is also due to the fact that students possess an intrinsic motivation that comes from beliefs, professional love, pro-activity, fear of public failure and predisposition to achievement which allows them to transform information and concepts that will encourage the development of skills related to their professional practice, converting them into self-regulated students, as affirmed $\underline{13}$. As well, student attitude and motivation are statistically related, that is, a motivated student is a student who possesses a positive attitude towards the task, which allows verifying the affirmations ${ }^{12}$. Also, the motivation considered personal and conscious that the university student adopts before his learning process when associating with perspectives of orientation towards the study, goals and personal motives turn him into a student with positive attitude towards the academic process which corroborates the criteria $a^{8-12}$.

In the same way, these relationships of significance allow us to infer that a student with a positive and motivated attitude towards the study is a self-regulated student in his/her academic process that is most likely to achieve academic success, which corroborates the criteria $\frac{15-19}{}$. Additionally, the self-regulated student is able to self- direct, self-monitor, self-evaluate and develop the ability to adapt to changes, which corroborates the criteria.

Figure 1 shows that almost half of the sample (100 cases, $46.3 \%$ ) has a low student attitude (AEB) and low self-regulation (ARB), which means that the predisposition, interrogation capacity, disposition to problematize, evaluation of the learning process, positivity and ability to learn to learn from this percentage of the population is low. This may be due to external factors related to the family, love for the profession or of another type. The $25.9 \%$ (56 cases) that correspond to almost a quarter of the sample are students who have a high student attitude but low self-regulation. This may be due to the fact that these students, despite having a positive predisposition and orientation towards success, are not organized, do not self-monitor what is reflected in their low self-regulation. The $21.8 \%$ (47 cases) that correspond to almost a fifth of the population are applied students, organized, self-direct and self-evaluate what is reflected in a high self-regulation. The $6 \%$ (13 cases) is an a-typical group since they are students who despite having a low student attitude have a high self-regulation which may be due to personal problems such as the economic support of their family nucleus, health problems, non-academic commitments but who knows that if they organize themselves self-regulating they can achieve academic success.

Figure 2 shows that the majority of students in the sample $46.3 \%$ (100 cases) have a high motivation towards learning, that is, students are aware of their training process with a high motivation oriented towards the study, with high personal reasons, with high attitude towards the task and professional goals according the criteria ${ }^{\frac{8-14}{}}$, but they present drawbacks of self-regulation manifested with low self-efficacy indexes, skills and strategies of planning and organization of academic activities, that is, in this particular population, they are met in very low grade the postulates $\frac{15-19}{10}$ it is likely that of these 100 cases a percentage will achieve academic success but others will not.

The $27.8 \%$ (60 cases) that correspond to almost a quarter of the population studied have low motivation and low self-regulation, confirming the statistical significance between these two variables. Low motivation can be attributed to the same student and same conscience that he adopts before his academic process. This is affected in one way or another by external factors that cause the loss of orientation towards the study, that is, in these students the precepts $s^{\frac{8-13}{13}}$ are met in low degree. Low self-regulation may not be due to the fact that it is a population that is 
more likely to be not intrinsically motivated, nor do they adapt easily to changes, making them inflexible students to adapt to changes. In addition, the fear of failure is not part of their motivation to obtain academic achievements, that is, in these students the statements of Lindner $\frac{19,13}{}$ are met in low grade.

The $4.2 \%$ ( 9 cases) have low motivation and high selfregulation, it is likely that this is because these students are students who are applied, organized and plan their academic exercise but when they join the class or training activity they do not do it of the best way. This may be due to internal or external factors such as love for the profession, didactic strategies, and teacher style among other aspects. This situation is strange, but cases like these occur despite the statistical significance among the variables. The $21.7 \%$ (47 cases) that correspond to almost a fifth of the studied population are categorized within the statistical significance between the variables, that is, the principle that the motivated student is a self-regulated student is met. In addition, it can be noted that this percentage together with $27.8 \%$ ( 60 cases) of low motivation and low self-regulation sum a total of $49.5 \%$, that is, the premise of correspondence between the motivation and self-regulation variables was verified in 107 cases.

Figure 3 shows that the majority of students in the sample $39.8 \%$ (86 cases) are within the statistical significance of the variables, i.e. that a motivated student is a student who has a high attitude towards learning, that is, in these students the declarations ${ }^{2,3}$ are fulfilled. In the same way these are students who evaluate their process and adopt positive attitudes according proposed ${ }^{4}$. Also, when there is a statistical significance between attitude and motivation; motivation and self-regulation as proposed $\underline{13}$ and between cognition and attitude according to ${ }^{\underline{Z}}$, we can conclude that these students are students whose attitude, motivation and self-regulation allow them to advance cognitive processes and achieve academic success. In addition, they are students who implicitly should have a high academic performance. The $28.2 \%$ (61 cases) that correspond to almost a quarter of the students under study have a high motivation but their predisposition is low, that is, their attitude towards learning is not the best. This could be explained because despite being students who have a long-term motivation to train as engineers, their predisposition and behavior in specific situations (behavior in certain subjects or classroom for various reasons) is not the best, that is, this group is characterized by this peculiarity.
The $23.6 \%$ (51 cases) that represent almost a quarter of the population, have the correspondence indicated by the statistical significance, that is, students with a low attitude correspond to a low motivation, this means that a student with a negative predisposition towards its academic exercise it manifests itself in a negative motivation towards its motivated learning activity, not fulfilling in this group the

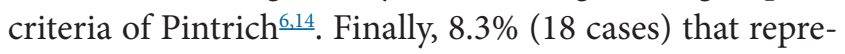
sent exactly one-twelfth of the population are interesting students to be subjected to a more rigorous study because despite having low motivation, they have a high attitude towards learning according to the criteria ${ }^{2,3}$ but not those of Pintrich ${ }^{14}$ related to motivated learning, which may be due to the students' lack of skills in acquiring self-efficacy strategies and which affects their disposition towards specific tasks.

Table 1. Chi-Square Test

\begin{tabular}{|c|c|c|c|}
\hline \multicolumn{4}{|c|}{ Self-regulation of learning } \\
\hline Variable & Chi-Square & $\begin{array}{c}\text { Degrees of } \\
\text { freedom } \\
(\mathrm{df})\end{array}$ & P value \\
\hline Student attitude & 31.28 & 1 & $0.00^{* *}$ \\
\hline Motivation & 8.76 & 1 & $0.0031^{* *}$ \\
\hline \multicolumn{5}{|c|}{ Student Attitude } \\
\hline Motivation & 19.77 & 1 & $0.0031^{* *}$ \\
\hline
\end{tabular}

Source: Author (2017)

** Relation with high statistical significance with confidence level of $95 \%$

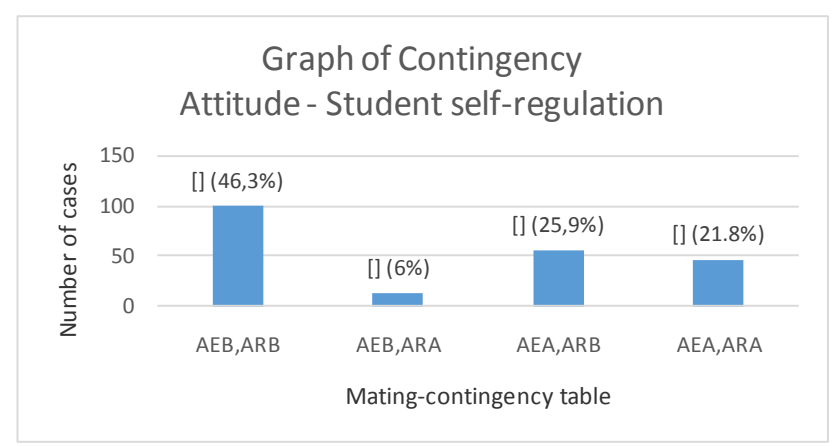

Source: Author (2017)

Figure 1. Attitude - student self-regulation. 


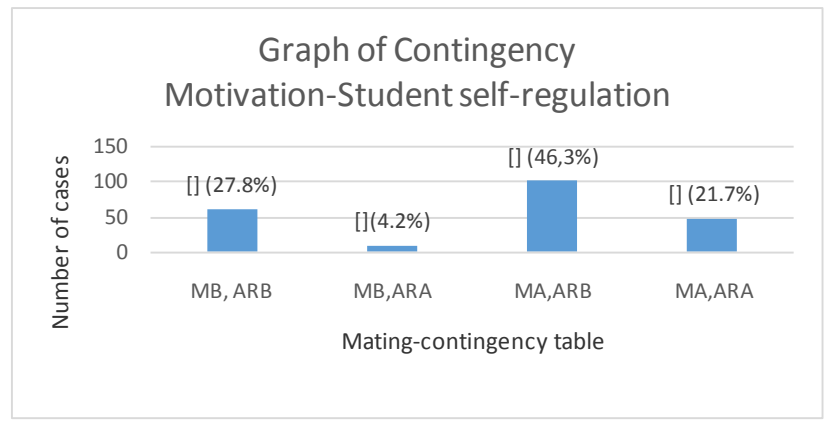

Source: Author (2017)

Figure 3. Motivation - student attitude.

\section{Conclusion}

The instrument for measuring Self-Regulation for Learning (SRLI) is considered as a reliable and effective tool. It allowed identifying weaknesses in the students that will serve to adopt strategies and advise the teaching-learning processes attending to the considerations that a self-regulated student must satisfy. In the case of engineering students at the University of Cartagena, the results reveal that there is a statistically significant relationship between the student attitude and the level of Self-Regulation for Learning (SRLI) at 95\% confidence level. That is to say, that a student of Engineering of the University of Cartagena fulfills his goals and academic achievements because they are self-regulated students. For this, it is necessary to implement workshops that allow the student, through the technique of questions and projects, to improve their predisposition towards learning. In the same way, case studies will encourage students to learn to interrogate, learn to learn and generate innovative solutions, facilitating their orientation towards success, encouraging their safety in decision making, understanding that the achievements are the result of their own effort, which will ultimately promote a positive attitude toward the teaching-learning processes in which they are involved.

On the other hand, the study also showed a statistically significant relationship at a $95 \%$ confidence level between student motivation and self-regulation for learning. This is probably due to the fact that the students surveyed consider their motivation as a result of the inclination in decision-making related to their own ideas and convictions learned in previous academic situations. That is to say, this allows them to acquire security in decisionmaking in order to solve problematic situations related to their area of professional performance. However, it was found that the motivation in the students was due mostly to personal aspects related to love for the career, personal goals, and professional and personal fulfillment goals. In the same way aspects related to academic reputation (intrinsic) are considered relevant during the self-regulated learning process.

The results also showed a statistically significant relationship between the student attitude and the motivation towards learning at $95 \%$ confidence level. This is probably due to the motivation of the student for the profession and the positive influence it receives from the academic environment (adequate library, technological tools, TIC, efficient classrooms, among others). In the same way, a motivated student has a great attitude towards meaningful learning since he is able to monitor himself and self-assess what will allow him to reorient his academic process aiming at strengthening the weaknesses found.

All this allows us to conclude that the Engineering students of the University of Cartagena are motivated students and that they have a great attitude towards success and with defined goals in the medium and long term.

\section{Acknowledgements}

This document is dedicated to our parents, colleagues and research professors, without which it would not have been possible to finalize this investigation.

\section{References}

1. Ministry of National Education of Colombia. 2017. https:// spadies.mineducacion.gov.co/spadies/consultas_predefinidas.html?2

2. Lopez BG, Perez PC, Carbonell BS. Behavior for learning and academic performance in university students. Iberoamerican Journal of Education. 2007 Feb; 42(1):1-11.

3. Heinz Von F. The perception of the future and the future of perception. Seeds of cybernetics. 1st ed. Editorial Gedisa: Barcelona, Espa-a. 1991. p. 1-7.

4. Bojorquez LR, Quiroz AU, Quiroz VU. The positive and negative attitudes of students in the learning of mathematics, its impact on failure and terminal efficiency. Ra Ximhai Magazine. 2014 Dec; 10(5):291-319.

5. Carre-o AB, Toscano OLD, Cruz M. Reasons, attitudes and learning strategies: Learning motivated in university students. Curriculum Magazine and Formation of the Professorship. 2012 Apr; 16(1):125-42. 
6. Fong W, Severiche C, Pitre R,Vargas L, Espinosa E. Association between Self-Regulation of Learning student attitude, provenance and age in engineering students. Contemporary Engineering Science. 2017 Sep; 10(14):66572. https://doi.org/10.12988/ces.2017.7765

7. Silva FW, Sierra SCA, Morales JJ, Ligardo MYA, Fuentes EEA. Cognition and its relationship with endogenous and exogenous factors in engineering students. International Journal of Applied Engineering Research. 2017 Sep; 12(17):6929-33.

8. Atkinson, J. An introduction to motivation. 1st ed. Oxford. England: D. Van No strand Company; 1964. p. 335.

9. Covington MV, Roberts BW. Self-worth and college achievement: Motivational and personality correlates. Student motivation, cognition, and learning: Essays in honor of Wilbert J. McKeachie. England. Lawrence Erlbaum Associates.1994. p. 157-87.

10. Boza A. Academic motivation in the university. En Steren dos Santos, differentes cenarios. Edipucrs; Porto Alegre. 2010. p. 1-9.

11. Ford M. Motivating humans: Goals, emotions and personal agency beliefs. New Bury Park: SAGE Publications; 1992. p. $1-302$.

12. Wigfield A, Eccles J. Expectancy value theory of achievement motivation. Contemporary Educational Psychology. 2000; 25(1):68-81. PMid:10620382. https://doi. org/10.1006/ceps.1999.1015

13. Ponton ELJ, Fong-Silva W, Borre DFA, Sierra CSA, Moncada JPD. Association between self-regulation of learning, motivation, teaching quality and sports dedication in engineering students. Contemporary Engineering Sciences. 2017 Oct; 10(18):891-99. https://doi.org/10.12988/ces.2017.7998

14. Pintrich P, Schunk D. Motivation in educational contexts. Madrid: Pearson; 2006. p. 1-71.

15. Lindner RW, Harris BR, Gordon WI. Teaching selfregulated learning strategies. Paper presented at the Annual Conference of the Association for Educational Communications and Technology; New Orleans, LA. 1993 Jan. p. 1-15.

16. Bandura A. Self-efficacy mechanism in human agency. American Psychologist. 1982 Feb; 37(2):122-47. https:// doi.org/10.1037/0003-066X.37.2.122

17. Schunk DH. Self-efficacy perspectives on achievement behavior. Educational Psychologist. 1984; 19(1):48-58. https://doi.org/10.1080/00461528409529281

18. Zimmerman B, Pons MM. Development of a structured interview for assessing student use of self-regulated learning strategies. American Educational Research Journal. 1986; 23(4):614-28. https://doi.org/10.3102/00028312023004614

19. Reinhard LW, Bruce RH. Self-Regulated Learning in Education Majors. The Journal of General Education. 1998; 47(1):62-78

20. Cronbach LJ. Coefficient alpha and the internal structure of tests. Psychometrika.1951; 16(3):297-334. https://doi. org/10.1007/BF02310555

21. Stevenson WJ, Aguilera OP. Statistics for administration and economy: Concept and application. 1st Ed. Mexico: Alfaomega; 1981. 